\title{
A Novel Approach for Efficient and Convenient E-Auction
}

\author{
Amita Chakraborty ${ }^{1}$, Md. Golam Moazzam², Shamima Nasrin ${ }^{1}$, Mohammad \\ Zahidur Rahman ${ }^{2}$ \\ ${ }^{1}$ Department of Computer Science and Engineering, Shaikh Burhanuddin College, Dhaka, Bangladesh \\ ${ }^{2}$ Department of Computer Science and Engineering, Jahangirnagar University, Dhaka, Bangladesh
}

\begin{abstract}
This paper presents a novel approach for efficient and convenient e-auction by comparing the performance between first-price and second-price sealed bid auction. This studied entry and bidding patterns in first-price and second-price sealed bid auction and documented a set of systematic effects on these two auctions. It is found that the first-price auction gives rise to larger levels of efficiency and revenue, but lower payoffs to the bidders. The latter finding is the second-price auction is a dominant strategy for a buyer to drop out of the bidding when the asking price reaches his or her valuation. This paper first demonstrates on the implementation of first-price and second-price sealed bid auction. Then it talks about the concerns about comparison between them.
\end{abstract}

Keywords: E-commerce, e-Auction, First-price sealed bid auction, Online sealed bid auction, Security and privacy, Vickrey auction.

\section{INTRODUCTION}

An auction is a process of buying and selling goods or services by offering them up for bid, taking bids, and then selling the item to the highest bidder. In economic theory, an auction may refer to any mechanism or set of trading rules for exchange [1]. There are several variations on the basic auction form, including time limits, minimum or maximum limits on bid prices, and special rules for determining the winning bidder(s) and sale price(s). Participants in an auction may or may not know the identities or actions of other participants [2], [3]. Depending on the auction, bidders may participate in person or remotely through a variety of means, including telephone and the internet. The seller usually pays a commission to the auctioneer or auction company based on a percentage of the final sale price.

The players in an auction include [4], [5]:

- Seller, who has one or more items to sell;

- The bidder who submit the bid;

- Auctioneer, who acts on behalf of the seller to determine a winning price and a bidder as the winner.

- Winner, the bidder chosen by the auctioneer(s) to pay the seller the clearing price and get the goods.

\section{SEALED BID AUCTION}

The sealed-bid auction has been a useful tool to distribute resources for many years. It usually contains four phases. Various sealing functions may be used to seal the bids and keep them secret before they are opened. Different auction rules may be used. Auctions have a long history since 500 B.C., when Herodotus reported the use of an auction. Auction was frequently used to liquidate property and estate goods during the Roman Empire. They are an effective method to distribute goods fairly. In a sealed-bid auction, a bidder has to submit a sealed bid before a closing time. After the closing time one or more auctioneers open the bids to decide the winners according to a predefined rule [6].

In the Internet era, electronic commerce is an important and popular industry. Electronic auction is a key function in e-commerce and can be used to distribute electronic as well as non-electronic goods effectively and fairly. Although still at its early stage, e-auction is developing fast. It is estimated that trade through internet auction systems in 1999 totals $\$ 4.5$ billion. The most famous e-auction website, e-bay, has more than two million visitors a day [7]. In a network environment, sealed-bid auction is preferred not only because of its convenience and quickness but also because of its potential ability to protect bid confidentiality and bidders' privacy.

\section{SEALED FIRST-PRICE AUCTION}

In a first-price sealed-bid auction, each bidder submits a sealed bid to the seller. This remains hidden from other bidders. The high bidder wins and pays his bid for the good. Generally, a sealed-bid format has two distinct parts: a bidding period in which participants submit their bids, and a resolution phase in which the bids are opened and the winner determined. 
When multiple units are being auctioned, the first-price sealed-bid auction is refered to as a discriminatory auction because not all winning bidders pay the same amount. It works as follows. In this auction, sealed bids are sorted from high to low, and items awarded at highest bid price until the supply is exhausted. The most important point to remember is that winning bidders can pay different prices. This kind of auction has the same structure than the second-price sealed-bid auction, except that in this case the winner of the auction pays his/her own bid for the item. Unlike the English auction, bidders never see their rivals' bids and can only submit one bid. This type of auctions are commonly used for selling mineral rights to U.S government-owned land, and sometimes used for selling artwork and real estate property. Also, their analysis can be used to understand tendering of government procurement contracts. Within the class of first-price, sealed-bid auctions, there are a number of possible variations in environment, information, and rules [8], [9]:

1. The number of potential bidders is either known, or unknown with a distribution that is common knowledge.

2. There may be no reservation price, so that the item will definitely be sold, or there may be a reservation price which is announced or unannounced in advance of the auction. If there is a reservation price that is unannounced, then it may be made known after the auction is complete or the item may simply be withdrawn from the auction. If there are ties, there may be a tie-breaking mechanism, or subsequent rounds of bids between those tied.

3. The winning bid may be announced, or may be private information shared by the winner and seller, so that non-winners have only the information that their bid was lower. Non-winning bids may be announced, or may be private information shared by a losing bidder and the seller. Finally, a third party acting as an agent for the seller and buyers may designate a winner without revealing the amounts of bids to either seller or buyers, or revealing the reservation price. Of course, if an item is sold, then the winning bid is known at least to the buyer and seller. These information differences are not germane in a one-shot auction, but are relevant if there is a possibility of resale or re-auction.

4. There may or may not be an opportunity for negotiation after the auction. One alternative is that bids are binding. Another is that they may contain contingencies whose value and prospects for clearing offer players the opportunity for post-auction negotiation. If such contingencies are allowed, then there must be a mechanism for terminating negotiations with the winning bidder if the contingencies are not satisfied, and negotiating with a lower bidder or re-starting the auction. An obvious consequence of allowing contingencies in bids is that setting contingencies becomes part of the bidder's strategy, where a high bid with contingencies offers the opportunity to engage in bilateral negotiations with less effective competition from potential rival buyers. Finally, if one player has a right of first refusal (RFR), then all bidders must take into account the possibility that this right will be exercised so that the RFR holder preempts the winning bidder and acquires the item at the winning bid, and that the item may subsequently be available following the auction through contracting with the party holding the RFR.

5. If the item is not sold, there may or may not be opportunities for the item to be re-auctioned. If the item is sold, there may or may not be opportunities for resale.

6. The value placed on the item by a potential buyer may be known to this buyer, may be unknown with a known distribution, or may be unknown with a distribution that is not completely known. This is also true for the seller. No player knows the value of any other player, but each player has beliefs about the distributions from which other player's values are drawn. These beliefs might be symmetric among all buyers, or not, and might be rational or not. The distribution of beliefs about a given player may be common to all other players, or may be specific to each other player. If there is uncertainty about values, it may be independent across players, or may contain common uncertainties. The information situation on buyer's values is critical if there is a possibility that the item will be withdrawn and subsequently re-auctioned to the same potential buyers.

\section{Bidding of First-Price Sealed-bid Auction}

It is obvious that in a first-price sealed-bid auction, a bidder always bids below her valuation for the item. If she bids at or above her value, then her payment equals or exceeds her value if she wins the auction, and therefore her expected profit will be zero or negative. Since bids are below bidders' values, the first-price sealed bid auction is not a demand revealing mechanism [10]. In a first-price sealed-bid auction, there is no sequential interaction among bidders. Bidders submit the bids only once. Bidders are trading between bidding high and winning more often, and bidding low and benefiting more if the bid wins. It can be shown that a symmetric Bayesian Nash Equilibrium in the first-price sealed-bid auction with risk neutral bidders is that every bidder bids the expected highest value among their rivals, conditional on the bidder's own value being higher than all of the rivals' values. The first price auction is strategically equivalent to the Dutch auction. Unlike in the second-price and English auctions, it is not a dominant strategy in a first-price auction to bid your value. However, the theoretically optimal bidding strategy in both first-price and Dutch auctions is the same for any given bidder. It is 
advantageous for a bidder to gather information about the competing bids before deciding on his own bid. Therefore, the privacy issue is essential in this auction format.

\section{VICKREY AUCTION}

Also known as a second-price auction, the Vickrey Auction procedure was developed by the economics professor William Vickrey and studied by Clarke and Groves. The bidding process in a Vickrey Auction is as follows [11], [12], [13]:

1. The bidders submit sealed bids to the auctioneer.

2. The auctioneer determines the allocation and pricing as follows:

(a) Allocation: The highest bidder (player 1) wins the item.

(b) Pricing: The winner pays the second highest bid (b2). All other players pay 0 .

\section{Basic features of the Vickrey Auction:}

- As proved by Vickrey, although the Vickrey auction is a one-shot auction, it is mathematically equivalent to the English auction.

- Rational players are encouraged to be truthful.

- The allocation produced maximizes social welfare in the sense that the bidder with the highest valuation indeed gets the item.

In a short, it can be said a Vickrey auction is a type of sealed-bid auction, where bidders submit written bids without knowing the bid of the other people in the auction. The highest bidder wins, but the price paid is the second-highest bid. Vickrey considered only auctions where a single, indivisible good is being sold. In this case, the terms Vickrey auction and second-price sealed-bid auction are equivalent, and are used interchangeably. When multiple identical units are being sold in a single auction, the most obvious generalization is to have all winning bidders pay the amount of the highest non-winning bid. This is known as a uniform price auction. The uniform-price auction does not, however, result in bidders bidding their true valuations as they do in a secondprice auction unless each bidder has demand for only a single unit.

\section{ALGORITHMS IN APPLICATION LEVEL FOR FIRST-PRICE AND VICKREY}

\section{Registration Phase} AUCTION

I. A dedicated registration server starts biding protocol by registering each bidder (Fig. 1).

II. For registration bidder must submit his information such as Bid deposit/Bank account/ Tax return papers, etc to registration Server.

III. Registration Server sends a certificate to bidder.

IV. An Independent private channel will be established between Auction server and client bidder through which they communicate with each other.

V.

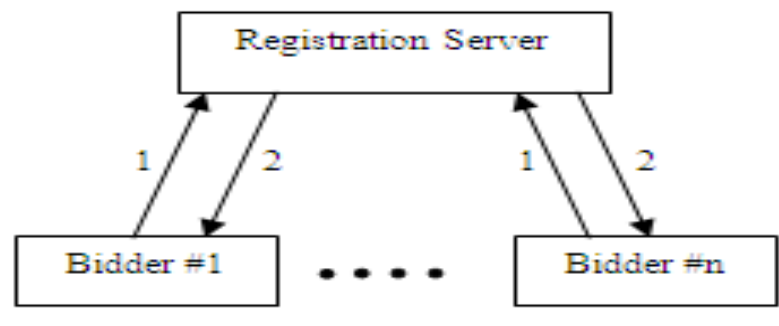

1. Bidder submit National Id, Email, etc

2. Registration server provides registration Id.

Fig. 1: Registration Phase

VI. After a pre-defined time registration process, maintained by time keeper, will time out. Then bidding process starts (Fig. 2).

\section{Bidding Phase}

I. Auction server starts it's bidding service and must close after a predefined time maintained by time keeper (Fig. 2).

II. Bidder generates his personal session key and ticket for specific bid.

III. For this bidder choose auction item, price quote, auction ID which form his secret bid.

IV. Bidder then randomly chooses a polynomial $f(\mathrm{x})$ of degree $t$ with a free term equal to secret bid. 
V. Then she/he computes the share of the secret bid from a pair of values of the two polynomials $\alpha_{i}=f(i)$ and $\rho_{i}$ $=r(\mathrm{I})$ based on the algorithm of the polynomial chosen, where $i$ is for $\mathrm{n}$ participating auction services.

VI. Before sending to the $i_{\text {th }}$ auction servers via private channel bidder encrypt his/her own bid.

VII. According to the protocol, the commitment of a share is the one way hash of that share.

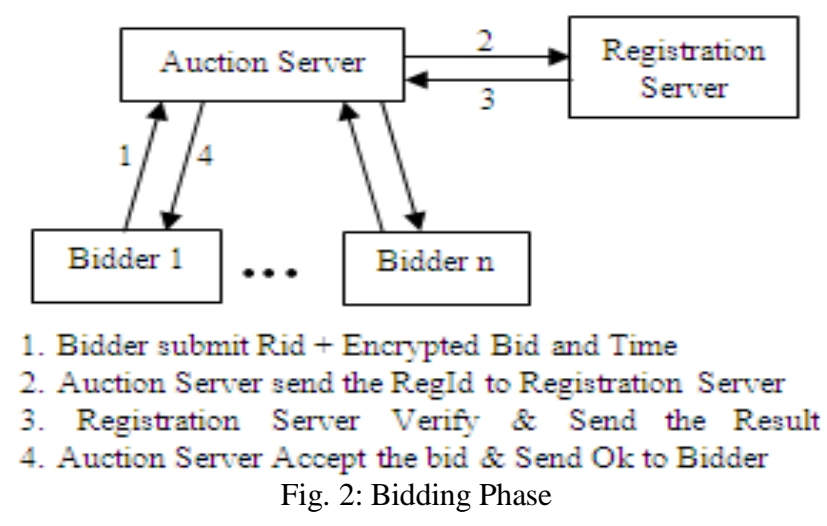

\section{Share Compare, Check Validity and Broadcast Integrity}

I. Compares the received pair of each encrypted $\alpha_{i}$ and $\rho_{i}$ with corresponding broadcast commitment.

II. Each auction server $(1,2 \ldots n)$ also verifies that the broadcasted polynomial lie within a committed polynomial.

III. If validity failed bidder then informed.

IV. When bidder receives any complaint from $\boldsymbol{i}_{\text {th }}$ auction server, then he/she openly broadcast his/her $\alpha_{i}$ and $\rho_{i}$ and commitment to defend integrity.

V. If he/she does not follow this step must be disqualified.

\section{Closing of Bids and Winner Declaration}

After completion of bidding phase reconstruction process of auction bid service manager (i.e. time keeper) collect all shares from all auction servers $(1,2 \ldots \mathrm{n})$ and reconstruct them and calculate the winner.

\section{Announcing Phase}

I. Auction bid service manager pass an auction list to the bidder when he/she ask for it. In auction list winner is declared.

II. Then Auction server asks for secret gammas to the claimed bidder as to proof he/she is the winner.

III. Auction server validates secret gammas and congratulates winner (Fig. 3).

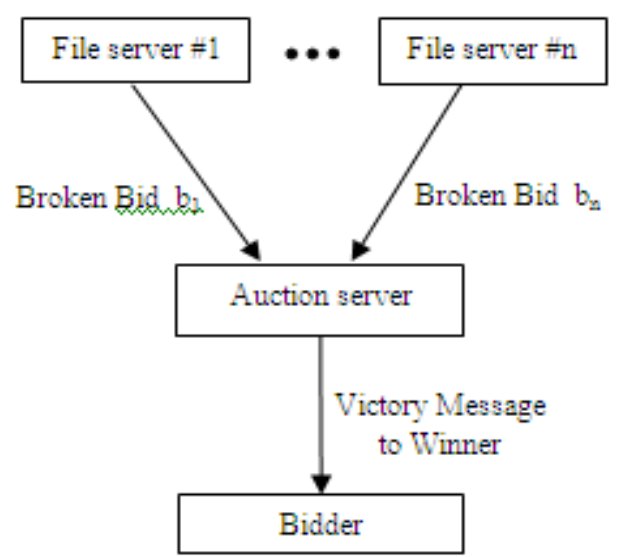

Fig. 3: Winner Selection Phase

\section{COMPARATIVE STUDY}

In a written auction, bidders are invited to submit a sealed bid, with the understanding that the item is awarded to the highest bidder. Under the first-price rule the winner actually pays as much as his own bid, whereas under the second-price rule the price is equal to the second highest bid. 
Table 1: Similarities in auction theory

\begin{tabular}{|c|c|}
\hline OPEN & CLOSED-SEAL BID \\
\hline \hline $\begin{array}{c}\text { ascending price } \\
\text { (English) }\end{array}$ & $\begin{array}{c}\text { second-price } \\
\text { (Vickrey) }\end{array}$ \\
\hline $\begin{array}{c}\text { descending price } \\
\text { (Dutch) }\end{array}$ & first-price \\
\hline
\end{tabular}

It's easy to see that an English auction produces the same revenue as a second-price auction: An English auction ends precisely when the second-highest bidder drops out although in some English auctions bidders must raise the high bid by some definite increment, in which case the winner pays marginally more than the secondhighest bid. The Dutch auction and the first-price auction are also equivalent to each other, since in a Dutch auction, the prize goes to the bidder willing to bid highest, and she pays what she bids.

\section{Self-revelation/Incentive Compatibility}

In a Vickrey auction with Independent Private Values (IPV) each bidder maximizes his or her expected utility by bidding his or her true valuation. It is a dominant strategy for a buyer to drop out of the bidding when the asking price reaches his or her valuation. Thus, just as in the Vickrey sealed second price auction, the price paid by the buyer with the highest valuation is equal to the second highest value.

\section{Ex-post Efficiency}

A Vickrey auction is ex-post-efficient under the most general circumstances. It thus provides a baseline model against which the efficiency properties of other types of auctions can be posited.

\section{WEAKNESSES}

Despite the Vickrey auction's strengths, it has shortcomings:

- It does not allow for Price discovery, that is, discovery of the market price if the buyers are unsure of their own valuations, without sequential auctions.

- Sellers may use shill bids to increase profit. In iterated Vickrey auctions, the strategy of revealing true valuations is no longer dominant.The Vickrey-Clarke-Groves (VCG) mechanism has the additional shortcomings:

- It is vulnerable to collusion by losing bidders. It is vulnerable to shill bidding with respect to the buyers.

- It does not necessarily maximize seller revenues; seller revenues may even be zero in VCG auctions. If the purpose of holding the auction is to maximize profit for the seller rather than just allocate resources among buyers, then VCG may be a poor choice. The seller's revenues are non-monotonic with regard to the sets of bidders and offers.

The non-monotonicity of seller's revenues with respect to bids can be shown by the following example. Consider 3 bidders A, B, and C, and two homogeneous items bid upon, $\mathrm{Y}$ and $\mathrm{Z}$. A wants both items and bids \$2 for the package of $\mathrm{Y}$ and $\mathrm{Z}$. B and $\mathrm{C}$ both bid $\$ 2$ each for a single item (bid $\$ 2$ for $\mathrm{Y}$ or $\mathrm{Z}$ ), as they really want one item but don't care if they have the second. Now, $\mathrm{Y}$ and $\mathrm{Z}$ are allocated to $\mathrm{B}$ and $\mathrm{C}$, but the price is $\$ 0$, as can be found by removing either B or C respectively. If $\mathrm{C}$ bid $\$ 0$ instead of $\$ 2$, then the seller would make $\$ 2$ instead of $\$ 0$. Because the seller's revenue can also go up when bids are increased, the seller's revenues are nonmonotonic with respect to bids. A purely superficial comparison of the first-price and second-price sealed-bid auctions might suggest that the seller would get more money for the item if he ran a first price auction: after all, he'll get paid the highest bid rather than the second-highest bid. It may seem strange that in a second-price auction, the seller is intentionally undercharging the bidders, but bidders in a first-price auction will tend to bid lower than they do in a second-price auction, and in fact this lowering of bids will tend to offset what would otherwise look like a difference in the size of the winning bid.

\section{CONCLUSION}

In this paper, concentration has been given on the comparison of first-price and second-price sealed bid auction. It has been observed that despite the attractive theoretical properties of the Vickrey auction format, bidders may fear truthful revelation of information to third parties with whom they will interact after the auction and bidders may fear auctioneer cheating. It is also vulnerable to bidder collusion. If all bidders in Vickrey auction reveal their valuations to each other, they can lower some or all of their valuations, while preserving who wins the auction. Furthermore, the payment of the winner in the sealed first-price auction is equal to the expected revenue in the sealed second-price auction. Thus, it can be concluded that first-price sealed bid auction is more efficient and convenient than Vickery method. 


\section{REFERENCES}

[1]. Doyle, Robert A.; Baska, Steve, History of Auctions: From ancient Rome to todays high-tech auctions, (November 2002)

[2]. Pekec, Aleksandar; Rothkopf, Michael H., Combinatorial Auction Design, Management Science NFORMS) 49 (11): 1485-1503, November 2003.

[3]. Krishna, Vijay, Auction Theory, San Diego, USA: Academic Press, ISBN 0-12-426297-X, 2002

[4]. Milgrom, Paul, Putting Auction Theory to Work, Cambridge, United Kingdom: Cambridge University Press, ISBN 0-521-55184-6, 2004.

[5]. Shubik, Martin, The Theory of Money and Financial Institutions: Volume 1, Cambridge, Mass., USA: MIT Press, pp. 213-219, ISBN 0-262-69311-9, March 2004.

[6]. Klemperer, Paul, Auctions: Theory and Practice, Princeton, N.J.: Princeton University Press, ISBN 0691-11925-2, 2004.

[7]. Benjamin Edelman, Michael Ostrovsky, and Michael Schwarz, Internet Advertising and the Generalized Second-Price Auction: Selling Billions of Dollars Worth of Keywords, American Economic Review 97(1), 2007 pp 242-259.

[8]. Smith, Charles W., Auctions: Social Construction of Value, University of California Press, ISBN 0-52007201-4, 1990.

[9]. Milgrom, P., Weber, R., A theory of auctions and competitive bidding, Econometrica 50 (5): 1089-1122, 1982.

[10]. Hal R. Varian, Position Auctions, International Journal of Industrial Organization, 2006,

[11]. Vickrey, William, Counterspeculation, Auctions, and Competitive Sealed Tenders, The Journal of Finance 16 (1): 8-37, 1961.

[12]. Lucking-Reiley, David, Vickrey Auctions in Practice: From Nineteenth-Century Philately to TwentyFirst-Century E-Commerce, Journal of Economic Perspectives 14 (3): 183-192, 2000.

[13]. Lawrence M. Ausubel, and Paul Milgrom, The Lovely but Lonely Vickrey Auction, Combinatorial Auctions, MIT Press, Chapter 1, p. 12, 2006.

Amita Chakraborty received her B.Sc. (Hons) in Electronics and Computer Science and MS in Computer Science and Engineering from Jahangirnagar University in 1997 and 2002 respectively. She is now an Assistant Professor in the Dept. of Computer Science and Engineering, Shaikh Burhanuddin College, Dhaka, Bangladesh.

Md. Golam Moazzam completed his B.Sc (Hons) in Electronics and Computer Science from Jahangirnagar University in 1997 and MS in Computer Science and Engineering from the same University in 2001, respectively. He is now an Associate Professor in the Dept. of Computer Science and Engineering, Jahangirnagar University, Dhaka, Bangladesh

Shamima Nasrin received her B.Sc. (Hons) in Electronics and Computer Science and MS in Computer Science and Engineering from Jahangirnagar University in 1998 and 2002 respectively. She is now a Lecturer in the Dept. of Computer Science and Engineering, Shaikh Burhanuddin College, Dhaka, Bangladesh.

Dr. Mohammad Zahidur Rahman is currently working as a Professor in the Department of Computer Science and Engineering, Jahangirnagar University, Savar, Dhaka-1342, Bangladesh. 